treatment upon diabetic mortality in Canada, where since 1922 insulin has been available for everyone who wished to have it. In certain age groups the mortality from diabetes is not coming down; it may even be going up, because there are now many more diabetics who reach the older age groups. When these people die, as even the diabetic must, the cause of death is usually stated to be diabetes. But in the earlier age groups, up to fifty years, diabetic mortality has markedly declined. From 1891 until 1920, before the use of insulin, the percentage mortality among diabetics up to 50 years of age remained steadily at about 45 per cent, that is, nearly half the cases died. Since 1922, when insulin began to be used, the mortality first steadily declined, and for 1929-33 has been about 15 per cent (statistics for Ontario). This great saving of human life, as well as of much suffering, must be ascribed to experimental work done upon animals, and Sir Edward Mellanby, in proposing a vote of thanks to the lecturer, bewailed the fact that it is necessary even now for scientific men to come forward and justify the use of animal experiments.

\section{Measurement of Mechanical Power}

IN a lecture on the measurement of mechanical power by Dr. C. V. Drysdale, delivered to the Junior Institution of Engineers, and published in its Journal of August, he points out the urgent demand there is for the accurate measurement of mechanical power under service conditions and how impossible it is to judge the relative merit of various mechanical devices without knowledge of this and the economy of the fuel used. In mercantile shipping, this is fully recognized and has led to great improvements in torsion meters. Many engineers are now studying the performance of aero engines especially at high altitudes, and this involves the making of power measurements, more especially at high altitudes during actual flight. The Royal Aircraft Establishment has now designed and constructed a mechanical power (watt) meter for air-screw testing. Utilizing the principle that a constantly excited generator produces an electromotive force proportional to the speed and that the torque is proportional to the current, it has constructed a mechanical power meter which acts satisfactorily. Alternating current at a frequency of 1,500 is supplied by a small wind-driven alternator on the plane. Records are given which prove that accurate testing of power during flight has been accomplished. Dr. Drysdale states that, of the millions of mechanically propelled vehicles in use, it is probably safe to say that not one per cent of their engines are working with anything like their maximum efficiency. One has only to watch the tuning up of an engine after decarbonization and regrinding of the valves to realize how much it depends upon the almost unaided judgment of the mechanic.

\section{The Agricultural Research Council}

THE third report of the Agricultural Research Council (London : H.M. Stationery Office. 5s. 6d.) surveys the research work aided from State sources during the period October 1935-September 1937. Besides its co-ordinating functions in respect of much of the work carried out at the various research institutes in Great Britain, and its advisory capacity as regards the Development Fund, the Council now possesses a field station of its own at Compton, Berks, where it is proposed to establish disease-free herds of cattle, pigs, etc., and to provide opportunities for experiments under scientifically controlled conditions on a larger scale than is ordinarily possible at any individual research institute. The first group of experiments with cattle will be concerned with contagious abortion and will involve the testing of various vaccines. Among other problems to be investigated are the causes of the unduly high death-rate among pigs and poultry, particular attention being paid to fowl paralysis as regards both its hereditary and its infectious aspects. A new interest of the Council was marked by the setting up of an equine research committee to deal mainly with horse diseases, a substantial aid for which is being provided by the Racecourse Betting Control Board. The review of the research work on foot-and-mouth disease recently undertaken by the Council is particularly appropriate in view of the serious outbreaks this year. The general conclusions are that in spite of the high cost and slow progress of the investigations, they should be continued in the hope that eventually measures will be found that will make possible some modification of the slaughter policy.

\section{League of Nations: Social Surveys}

THE report on the work of the Advisory Committee on Social Questions of the League of Nations in 1938 (Second Session) refers to the proposed review of social questions to be published quarterly, and contains, in addition to information regarding the League's work on social questions, special articles by experts and selected bibliographies on social questions (C.147.M.88,4. Pp. 28. Geneva : League of Nations ; London: George Allen and Unwin, Ltd. 1s. 3d.). On the recommendation of a sub-committee, the Committee has decided to place three new subjects on its agenda : the principles adopted in the organization and administration of welfare work among the young, including social assistance; the training of persons engaged in social work; and family desertion. The first study is to be limited, in the first instance, to a selected number of representative countries, emphasis being placed on the study of principles adopted in organization and administration of the administrative machinery. The study on training for social work will take note of the work already carried out by the International Committee on Social Service Schools in regard to the participation of universities in the training of social workers, and will deal with other aspects, such as the extent to which different groups of social workers, including voluntary workers, are trained, and the training given. Developments in child welfare in the past year are summarized in the report, which includes reports from the liaison officers with the International Labour Office and the Health Organisation, and formulates the broad principles arrived at from its investigations on the placing of children in families. 